\title{
INCENTIVOS FISCALES PARA FOMENTAR ACTUACIONES DE MEJORA EN LA EFICIENCIA ENERGÉTICA DE VIVIENDAS DE CONSTRUCCIÓN ANTIGUA
}

\author{
MilenKa VillCa Pozo \\ Profesora de Derecho Financiero y Tributario \\ Universitat Rovira $i$ Virgili \\ milenka.villca@urv.cat
}

Recibido: 2 de octubre de 2017 / Aceptado: 27 de noviembre de 2017

RESUMEN: Atendiendo a los objetivos que persigue el Real Decreto 235/2013, de 5 de abril, en relación con la exigencia de la certificación de eficiencia energética de las edificaciones nuevas y antiguas, desde el panorama tributario, se analiza si existen incentivos fiscales que promuevan la eficiencia energética de los edificios de construcción antigua. Del análisis de la normativa de los tributos que inciden en la propiedad, como son el Impuesto sobre el Patrimonio e Impuesto sobre Bienes Inmuebles, se evidencia que carecen de elementos que fomenten el uso de energías renovables, no existiendo exenciones en favor de las instalaciones que usen dichas energías. En el Impuesto sobre Construcciones, Instalaciones y Obras apenas subsiste una bonificación potestativa. La situación no cambia en la imposición de la electricidad. Tales circunstancias nos conducen a examinar la conveniencia de introducir determinados incentivos fiscales en los impuestos que inciden en la propiedad, determinando en cuál de ellos tendría mejor cabida. Como conclusión se observa justificable la incorporación de incentivos, plasmados en deducciones, con vinculación a la vivienda habitual, porque la propiedad tiene vocación perpetua con aptitud conservadora que la hace mejor para gestionar el ahorro energético.

ABSTRACT: According to the objectives of the Real Decreto 235/2013 of April 5, and regarding the requirement of energy certification of new and existing buildings, we analyze from the fiscal perspective if there are tax incentives that promote the energy certification of existing buildings. By analyzing the tax regulations that have implications on property, like the Impuesto sobre el Patrimonio (Wealth tax) and the 
Impuesto sobre Bienes Inmuebles (Property tax) it is evident that both lack in elements to promote the use of renewable energies since there are no tax exemptions for those buildings that use this kind of energies. In the case of the Impuesto sobre Construcciones, Instalaciones y Obras (Tax on construction, installations and works) there is only the option of a voluntary tax reduction. And, the situation is not too different regarding the imposition of electricity. Such circumstances encourage us to evaluate the convenience of introducing certain tax incentives in relation to those taxes related to property, and determine in which of them it will be best to do it. As a conclusion, it can be said that the inclusion of such incentives is necessary. These incentives can be laid down as tax reductions linked to main residences, since this kind of property is characterized by perpetuity and the need of conservation, which makes them more suitable for investment in energy saving.

RESUM: Atenent als objectius que persegueix el Reial Decret 235/2013, de 5 d'abril, en relació amb l'exigència de la certificació d'eficiència energètica de les edificacions noves i antigues, des del panorama tributari, s'analitza si existeixen incentius fiscals que promoguin l'eficiència energètica dels edificis de construcció antiga. De l'anàlisi de la normativa dels tributs que incideixen en la propietat, com són l'Impost sobre el Patrimoni i Impost sobre Béns Immobles, s'evidencia que manquen d'elements que fomentin l'ús d'energies renovables, no existint exempcions en favor de les instal-lacions que usin aquestes energies. En l'Impost sobre Construccions, Instal-lacions i Obres només subsisteix una bonificació potestativa. La situació no canvia en la imposició de l'electricitat. Tals circumstàncies ens condueixen a examinar la conveniència d'introduir determinats incentius fiscals en els impostos que incideixen en la propietat, determinant en quin d'ells tindria millor cabuda. Com a conclusió s'observa justificable la incorporació d'incentius, plasmats en deduccions, amb vinculació a l'habitatge habitual, perquè la propietat té vocació perpètua amb aptitud conservadora que la fa millor per gestionar l'estalvi energètic.

PALABRAS CLAVE: eficiencia energética - impuestos - incentivos fiscales vivienda.

KEY WORDS: energy efficiency - taxes - tax incentives - house buildings. 
PARAULES CLAU: eficiència energètica - impostos - incentius fiscals - habitatge.

Sumario: I. Introducción. II. Regulación impositiva actual e incidencia en la eficiencia energética de la vivienda. 1. Impuestos sobre el Patrimonio (IP). 2. Impuesto sobre la Renta de las Personas Físicas (IRPF). 3. Impuesto sobre Transmisiones Patrimoniales (ITP). 4. Impuesto sobre Bienes Inmuebles (IBI). 5. Impuesto sobre Construcciones, Instalaciones y Obras (ICIO). 6. Impuesto sobre la electricidad. III. Creación de incentivos físcales para la mejora de la eficiencia energética en viviendas de construcción antigua. 1. Justificación de su creación. 2. Su "vinculación" con la propiedad. 3. Configuración, delimitación y transcendencia. IV. Reflexiones finales. V. Bibliografía.

\section{INTRODUCCIÓN}

A diferencia de lo que sucede en otros sectores como el automovilismo o el de los electrodomésticos, en el sector de la vivienda la eficiencia energética juega aún un papel secundario, puesto que al comprar una vivienda muy rara vez se pregunta por el consumo y estado energético del inmueble.

Pese a que la obligación de disponer del certificado de eficiencia energética de los edificios de construcción nueva y existente es exigible desde junio de $2013^{1}$ por disposición del Real Decreto 235/2013, de 5 de abril ${ }^{2}$, por el que se aprueba el procedimiento básico para la certificación de la eficiencia energética de los edificios, el mismo se ha convertido en un trámite más a realizar antes de celebrar un contrato de compraventa o arrendamiento y no va más allá del cumplimiento de esta obligación.

El certificado de eficiencia energética facilita la información del estado energético del inmueble, sin embargo no obliga al propietario o titular a llevar a cabo las medidas de mejoras propuestas en dicho certificado ${ }^{3}$. Es por ello que hoy por hoy compradores, propietario e inquilinos continúan subestimando el consumo energético de su vivienda, cuando habría de ser lo contrario, puesto que la eficiencia energética, entendida como la reducción de la energía utilizada para un determinado servicio (como la calefacción,

\footnotetext{
1 Así, el artículo 14 del Real Decreto 235/2013 establece que "cuando un edificio se venda o alquile, antes de su construcción, el vendedor o arrendador facilitará su calificación energética de proyecto expidiéndose el certificado del edificio terminado una vez construido el edificio".

2 BOE núm. 89, de 13 de abril 2013. El Real Decreto 235/2013, de 5 de abril, refundió el Real Decreto 47/2007, de 19 de enero, por el que se aprobó el Procedimiento básico para la certificación de eficiencia energética de edificios de nueva construcción en transposición de las exigencias relativas a la certificación energética de edificios establecidas en la Directiva 2002/91/CE del Parlamento Europeo y del Consejo, de 16 de diciembre de 2002. Además de refundir la norma citada, el Real Decreto 235/2013 transpuso parcialmente la Directiva 2010/31/UE del Parlamento Europeo y del Consejo, de 19 de mayo de 2010, en lo relativo a la certificación de eficiencia energética de edificios, de manera que incorporó el procedimiento básico para la certificación de eficiencia energética de edificios existentes, dejando así completo el procedimiento de certificación tanto de edificios nuevos como de edificios existentes, que era lo que faltaba en el ahora derogado Real Decreto 47/2007.
}

${ }^{3}$ Art. 6 del Real Decreto 235/2015. 
iluminación, aire acondicionado) o nivel de actividad $^{4}$, representa un importante potencial para mitigar los efectos del consumo energético y su impacto en el problema mundial del cambio climático.

Obsérvese que el 30,4\% del consumo de energía final de España se produce en edificios de viviendas y servicios ${ }^{5}$ y las emisiones de gases de efecto invernadero originada por los edificios han aumentado más de un $20 \%$ desde $1990^{6}$. Los estudios y datos estadísticos en realidad registran muy poco avance en la materia. Según el Instituto para la Diversificación y Ahorro de la Energía, hasta finales de 2015, de los 25 millones de viviendas que hay en España solo 1,5 millones tenían el certificado energético y aunque más del $50 \%$ de los propietarios españoles conoce la existencia de la certificación energética, solo un $36 \%$ la tendría en cuenta a la hora de vender o alquilar una vivienda ${ }^{7}$. Ahora bien, de los más de 25 millones de viviendas que existen en el país, 6 millones tienen más de 50 años, el 58\% de los edificios españoles se ha construido sin ningún criterio de eficiencia, y el 90\% son anteriores a la aplicación del Código Técnico de la Edificación $(\mathrm{CTE})^{8}$, norma que en 2007 incorporó las exigencias relativas a la eficiencia energética de los edificios residenciales y comerciales de nueva construcción en atención a la Directiva 2002/91/CE del Parlamento Europeo y del Consejo, de 16 de diciembre, relativa a la eficiencia energética de los edificios.

Estas circunstancias nos llevan a examinar en el trabajo, desde la perspectiva tributaria, si en los impuestos directos (como el Impuesto sobre la Propiedad e Impuesto sobre la Renta de las Personas Físicas), indirectos (Impuesto sobre Transmisiones Patrimoniales

\footnotetext{
${ }^{4}$ ARANDA USÓN, A., et. al.: Eficiencia energética en instalaciones y equipamiento de edificios, Ed. Prensas Universitarias de Zaragoza, Zaragoza, 2010, p. 50; World Energy Council (WEC): Survey of Energy Resources. Londres, Reino Unido, 2010, p.201. Recuperado el 10-9-2017, de https://www.worldenergy.org/wp-content/uploads/2012/09/ser_2010_report_1.pdf.

${ }^{5}$ Instituto para la Diversificación y Ahorro de la Energía: "Las claves para conocer y actuar en materia de Certificación Energética de los Edificios", 2015. Recuperado el 10-9-2017, de http://www.idae.es/uploads/documentos/documentos_Las_claves_para_conocer_y_actuar_en_materia_de _CEE_20151007_Comentarios_d3402fed.pdf.

${ }^{6}$ RUIZ RIVERA, R.: Calificación energética de los edificios.ENACO108, $1^{\circ}$ Ed., IC Editorial, Málaga, 2014. Recuperado el 10-9-2017, https://books.google.es/books?id=jNKNCwAAQBAJ\&pg=PT69\&dq=las+viviendas+en+Espa\%C3\%B1a + consumen + el $+17 \% 25+$ de + toda + la + energia + del + pais $\&$ hl $=$ es.

${ }^{7}$ Instituto para la Diversificación y Ahorro de la Energía: "Las claves para conocer y actuar en materia de Certificación Energética de los Edificios”, 2015, p. 1. Recuperado el 10-9-2017, de http://www.idae.es/uploads/documentos/documentos_Las_claves_para_conocer_y_actuar_en_materia_de _CEE_20151007_Comentarios_d3402fed.pdf.

${ }^{8}$ Ibídem, p. 1. El Código Técnico de la Edificación fue aprobado por el Real Decreto 314/2006, de 17 de marzo, y publicado en BOE núm. 74, de 28 de marzo 2006.
} 
y Actos Jurídicos Documentados) y municipales (Impuesto sobre Bienes Inmuebles e Impuesto sobre Construcciones, Instalaciones y Obras) que inciden en la propiedad existen incentivos fiscales que promuevan o fomenten la mejora de la eficiencia energética en la vivienda habitual del contribuyente. Examinamos también el Impuesto sobre la Electricidad puesto que índice directamente sobre la producción de energía eléctrica. El análisis se centra especialmente en el caso de las viviendas de construcción antigua (más de 30 años) porque el CTE, tal como vimos, obliga a construir los nuevos edificios observando un nivel de alta eficiencia, bien sea A o B, sin embargo en lo que respecta a los edificios existentes (anteriores a 2007) no existe normativa para motivar su renovación.

\section{REGULACIÓN IMPOSITIVA ACTUAL E INCIDENCIA EN LA EFICIENCIA ENERGÉTICA DE LA VIVIENDA}

\section{Impuestos sobre el Patrimonio (IP)}

En el $\mathrm{IP}^{9}$ no encontramos incentivos relacionados con la eficiencia energética de las propiedades o viviendas. La Ley 19/1991, de 6 de junio, del Impuesto sobre el Patrimonio $^{10}$, regula el IP como un impuesto directo y personal que grava el patrimonio neto de las personas físicas ${ }^{11}$, sin prever alguna exención, deducción o bonificación que pueda practicar el titular de la vivienda dotada de instalaciones de ahorro energético o cuando la misma posea buenas características y acondicionamientos energéticos.

La única exención relacionada con la vivienda habitual viene recogida en el artículo 4.Nueve de la Ley 19/1991, el cual dispone que tal exención operará siempre que se trate de la vivienda habitual del contribuyente (definida según la Ley 35/2006) y ésta tenga un valor máximo de 300.000 euros.

La exención que acabamos de apuntar, como se aprecia, tiene alcance general sobre la vivienda habitual del contribuyente cuyo el importe máximo sea de 300.000 euros, de

\footnotetext{
${ }^{9}$ El IP, después de haber sido suprimido en 2008, ha sido restablecido con carácter temporal para los ejercicios 2011 y 2012 (Real Decreto-ley 13/2011, de 16 de septiembre), siendo prorrogado posteriormente para 2013 (La Ley 16/2012, de 27 de diciembre), 2014 (La Ley 22/2013, de 23 de diciembre), 2015 (Ley 36/2014, de 26 de diciembre), 2016 (Ley 48/2015, de 29 de octubre) y 2017 (Real Decreto-ley 3/2016, de 2 de diciembre).

${ }^{10}$ BOE núm 136 de 7 junio 1991.

${ }^{11}$ Art. 3 de la Ley 19/1991.
} 
manera que en el caso de que el valor de la vivienda supere dicho umbral pasará a encontrarse gravada por el IP indistintamente si la vivienda reúne o no buenas características y acondicionamientos energéticos debido a que el precepto señalado no hace mención alguna a este aspecto en particular.

\section{Impuesto sobre la Renta de las Personas Físicas (IRPF)}

En este impuesto existía un incentivo fiscal que incidía significativamente en la mejora de la vivienda habitual y la eficiencia energética de la misma. Hablamos específicamente de la deducción por rehabilitación de la vivienda habitual, introducido por el Real Decreto-ley 6/2010, de 9 de abril, de Medidas para el impulso de la recuperación económica y el empleo ${ }^{12}$, y suprimido por la Ley 16/2012, de 27 de diciembre, de Diversas medidas tributarias dirigidas a la consolidación de las finanzas públicas y al impulso de la actividad económica ${ }^{13}$, con efectos a partir de 1 de enero de $2013^{14}$. Este incentivo, como se aprecia, tuvo un carácter temporal porque estuvo vigente desde el 14 de abril de 2010 hasta el 31 de diciembre de 2012.

Merece la pena profundizar en este incentivo, pese a que no se encuentra vigente, por cuanto ha incidido especialmente en la mejora energética de la vivienda y edificios. Su configuración estaba centrada en obras de mejora de la vivienda habitual y edificios que potencien la eficiencia energética de la misma (mediante instalación de paneles solares, mejora de la envolvente térmica del edificio y los sistemas de instalaciones térmicas), además de la higiene, salud y protección del medio ambiente, uso de energías renovables, la seguridad y la estanqueidad, la sustitución de las instalaciones de electricidad, agua, gas u otros suministros, la accesibilidad al edificio o la vivienda ${ }^{15}$. Así como también obras de instalación de infraestructuras de telecomunicación que

\footnotetext{
${ }^{12}$ El incentivo fue prorrogado en el 2011 por disposición del Real Decreto-ley 5/2011, de 29 de abril, de medidas para la regularización y control del empleo sumergido y fomento de la rehabilitación de viviendas (BOE núm. 108 de 6 mayo 2011).

${ }^{13}$ BOE núm. 312 de 28 diciembre 2012.

${ }^{14} \mathrm{Se}$ estableció un régimen transitorio para los contribuyentes que hubieran satisfecho cantidades con anterioridad a 1 de enero de 2013 por obras de rehabilitación o ampliación de la vivienda habitual o instalaciones de adecuación de la vivienda habitual de las personas con discapacidad, siempre que las mismas estén terminadas antes de 1 de enero de 2017 (art.1).

${ }^{15}$ Según los términos previstos en el Real Decreto 2066/2008, de 12 de diciembre, por el que se regula el Plan Estatal de Vivienda y Rehabilitación 2009-2012.
} 
permitan el acceso a Internet y a servicios de televisión digital en la vivienda habitual del contribuyente.

El texto vigente a partir de 14/4/2010 de la Disposición adicional vigésima novena de la Ley 35/2006, de 28 de noviembre, del Impuesto sobre la Renta de las Personas Físicas ponía de relieve particularmente en obras que consistan en "la sustitución de las instalaciones de electricidad, agua, gas u otros suministros", con la única prohibición de aplicar la deducción en obras que se realicen en plazas de garaje, jardines, parques, piscinas e instalaciones deportivas y otros elementos análogos. La deducción obviamente estaba supeditada a determinados requisitos y circunstancias establecidos a tal fin ${ }^{16}$.

Cabe destacar que esta deducción por rehabilitación venía vinculada al Plan Estatal de Vivienda y Rehabilitación 2009-2012 que fue aprobada por el Real Decreto 2066/2008, de 12 de diciembre. Se establecía pues que la rehabilitación sea realizada según los términos del Plan Estatal. Así, bajo el título de "Ayudas RENOVE de rehabilitación y eficiencia energética" el Capítulo IV del Real Decreto 2066/2008 contenía una lista taxativa de actuaciones protegidas para su financiación en el marco del objetivo de reforzar la rehabilitación y mejora del parque de viviendas ya construido con respeto del medio ambiente e impulso hacia una mayor eficiencia energética en las nuevas construcciones ${ }^{17}$.

Hoy en día, como indicamos al inicio, en el IRPF no se recoge ningún tipo de deducción relacionado con la rehabilitación o reformas de la vivienda así como por inversión en vivienda habitual.

\section{Impuesto sobre Transmisiones Patrimoniales (ITP)}

\footnotetext{
${ }^{16}$ Estos requisitos son: que la base imponible de los contribuyentes sea inferior a 53.007,20 euros anuales (desde 14/4/2010 a 6/5/2011) e inferior a 71.007,20 euros anuales (desde 7/5/2011 a31/12/2012); que las cantidades satisfechas en este concepto se realicen mediante tarjeta de crédito o débito, transferencia bancaria, cheque nominativo o ingreso en cuentas en entidades de crédito, a las personas o entidades que realicen tales obras, menos entrega de dinero de curso legal (Disposición adicional vigésima novena, Ley 35/2006; Disposición final primera del Real Decreto-ley 5/2011, de 29 de abril).

${ }^{17}$ Véase el artículo 58 del Real Decreto 2066/2008.
} 
Pese a que el Impuesto sobre Transmisiones Patrimoniales y Actos Jurídicos Documentados, en su modalidad de transmisiones patrimoniales ${ }^{18}$, tiene alcance colateral sobre la propiedad - por cuanto grava la transferencia de la propiedad de bienes inmuebles de "segunda mano", en tanto que la transferencia de "primera mano" o nueva construcción está sujeta al Impuesto sobre el Valor Añadido-, en su estructura no encontramos incentivos centrados en la eficiencia energética. Tal aspecto resulta lógico debido a que el hecho imponible del ITP recae exclusivamente en la "transferencia de la propiedad" y no en otros aspectos sustantivos de la misma.

\section{Impuesto sobre Bienes Inmuebles (IBI)}

Según la configuración dada por el Real Decreto Legislativo 2/2004, de 5 de marzo, por el que se aprueba el texto refundido de la Ley Reguladora de las Haciendas Locales $\left(\right.$ TRLHL) ${ }^{19}$, el IBI carece de elementos que fomenten el uso de energías renovables ${ }^{20}$. Se podría decir que el artículo 74.5 del TRLHL apenas hace referencia a una bonificación potestativa mediante la cual se faculta a los ayuntamientos a regular a través de ordenanzas fiscales una bonificación de hasta el 50 por ciento de la cuota íntegra del IBI para los bienes inmuebles en los que se haya instalado sistemas para el aprovechamiento térmico o eléctrico de la energía proveniente del sol.

Esta previsión permite constatar, por un lado, que al tratarse de una bonificación potestativa y no una bonificación obligatoria (como las que regula el articulo 74 TRLHL), la posibilidad de incorporar tal bonificación en la ordenanza fiscal que regula en IBI en el determinado municipio puede darse como no; y por otro lado, que esta bonificación potestativa tiene un carácter restrictivo por cuanto refiere exclusivamente a la instalación térmica o eléctrica proveniente de la energía del sol y no de otras fuentes de energías "limpias", como la energía eólica y de las mareas.

\section{Impuesto sobre Construcciones, Instalaciones y Obras (ICIO)}

\footnotetext{
${ }^{18}$ Regulado por los artículos 7 a 18 del Real Decreto Legislativo 1/1993, de 24 de septiembre, por el que se aprueba el Texto refundido de la Ley del Impuesto sobre Transmisiones Patrimoniales y Actos Jurídicos Documentados (BOE núm. 251 de 20 octubre 1993).

${ }^{19}$ BOE núm. 59 de 9 marzo 2004.

${ }^{20}$ ANGULO ARAMBURU, J.; CHICO DE LA CÁMARA, P.; GARCÍA BAQUERO, C.; HERRERA MOLINA, P.; MONREAL PALOMINO, I.: “El tratamiento fiscal de las nuevas...” ob. cit., p.261.
} 
Como tributo indirecto que grava la realización, dentro del término municipal, de cualquier construcción, instalación u obra para la que se exija obtención de la correspondiente licencia de obras, el ICIO viene dotado de una bonificación potestativa relacionada con la energía solar.

Nos referimos concretamente a la bonificación ambiental que establece el artículo 103.2, b) de TRLHL cuyo texto literal dice: "una bonificación de hasta el 95 por ciento a favor de las construcciones, instalaciones u obras en las que se incorporen sistemas para el aprovechamiento térmico o eléctrico de la energía solar. La aplicación de esta bonificación estará condicionada a que las instalaciones para producción de calor incluyan colectores que dispongan de la correspondiente homologación de la Administración competente".

El legislador ciertamente ha previsto un incentivo ambiental para las obras o instalaciones que incorporen sistemas para el aprovechamiento térmico o eléctrico de la energía solar para autoconsumo. Sin embargo, se observan tres aspectos en su regulación.

Primero, que la bonificación es potestativa por tanto se deja a los ayuntamientos la libertad de su incorporación o no $^{21}$. Segundo, que no se regula en profundidad los demás aspectos sustantivos y formales de la bonificación, quedando esto en facultad de cada ayuntamiento para su regulación en la Ordenanza fiscal del impuesto. Y tercero, en la bonificación no se tiene en cuenta ni se la adecua a las exigencias de ahorro de energía que establece el Documento Básico DB-HE "Ahorro de Energía" del Código Técnico de la Edificación ${ }^{22}$.

Tal aspecto es relevante y habría sido una buena oportunidad para remodelar la bonificación, puesto que el Documento Básico DB-HE ha sido actualizado recientemente por la Orden FOM/1635/2013, de 10 de septiembre ${ }^{23}$, y establece las reglas y exigencias mínimas para el ahorro energético de los edificios de nueva construcción y ampliaciones de edificios existentes, con el objetivo de conseguir «edificios de consumo de energía casi nulo» antes del 31 de diciembre de 2020. Todo ello en cumplimiento de las disposiciones que introdujo la Directiva 2010/31/UE del

\footnotetext{
${ }^{21}$ La única bonificación obligatoria del ICIO, que prevé el art. 159.2 del TRLRHL, es aplicable a las ciudades de Ceuta y Melilla, con una bonificación del 50 por ciento en la cuota tributaria.

${ }^{22}$ Aprobado por Real Decreto 314/2006, de 17 de marzo (BOE núm. 74 de 17 marzo 2006).

${ }^{23}$ BOE núm. 219 de 12 septiembre 2013.
} 
Parlamento Europeo y del Consejo, de 19 de mayo de 2010, relativa a la efíciencia energética de los edificios.

\section{Impuesto sobre la electricidad}

Dejando de lado la imposición sobre la propiedad y atendiendo al campo de la energía eléctrica también podemos constatar que el Impuesto sobre la Electricidad ${ }^{24}$, que grava la producción de energía eléctrica, no constituye un impuesto a través del cual se incentive al uso de energías renovables menos dañosas con el medio ambiente, porque es un impuesto cuya regulación no contiene ninguna norma que discrimine la tributación en función del origen de la electricidad ${ }^{25}$.

La base imponible del impuesto tiene carácter monetario y, por regla general, el impuesto se aplica con independencia del origen de la electricidad ${ }^{26}$. Por este motivo algunos autores han afirmado que con la creación de este impuesto se ha desaprovechado la ocasión de incluir la finalidad medioambiental en su estructura ${ }^{27}$.

\section{CREACIÓN DE INCENTIVOS FISCALES PARA LA MEJORA DE LA EFICIENCIA ENERGÉTICA EN VIVIENDAS DE CONSTRUCCIÓN ANTIGUA}

Frente a la ausencia de incentivos fiscales en la regulación actual de los impuestos que inciden en la propiedad cabe valorar la introducción de los mismos con el propósito de promover el ahorro energético a través de la vía fiscal puesto que mediante esta vía se

\footnotetext{
${ }^{24}$ Creado a través de la Ley 66/1997, de 30 de diciembre, de Medidas fiscales, administrativas y del orden social, publicado en BOE núm.313, de 31 diciembre 1997. Cabe destacar que un estudio completo sobre la fiscalidad de la energía se puede consultar en ROZAS VALDÉS, J. A.: «Evolución y reforma del sistema financiero de la energía eléctrica», Crónica Tributaria, nº 150, 2014, pp. 197-233.

25 GARCÍA-TORRES FERNÁNDEZ, M.J.: "La protección atmosférica en Andalucía: Estudio del gravamen sobre las emisiones a la atmósfera", en Derecho, Globalización, Riesgo y Medio ambiente, Ed. Tirant lo Blanch, Valencia, 2012, p.851.

${ }^{26}$ ANGULO ARAMBURU, J.; CHICO DE LA CÁMARA, P.; GARCÍA BAQUERO, C.; HERRERA MOLINA, P.; MONREAL PALOMINO, I.: El tratamiento fiscal de las nuevas energías, en A. Gago y X. Labandeira (dirs.), Energía, Fiscalidad y Medio ambiente en España, Ed. Instituto de Estudios Fiscales, Madrid, 2002, p.258.

${ }^{27}$ P. CHICO DE LA CÁMARA, P.; GRAU RUIZ, M. A.; HERRERA MOLINA, P.: "Incentivos a las energías alternativas como instrumento de desarrollo sostenible", Quincena Fiscal, Núm. 2/2003, pp. 930; ROZAS VALDÉS, J.A.: "El impuesto sobre la electricidad”, en R. Falcón y Tella (Dir.), Medidas Fiscales para 1998, Ed. Marcial Pons, Madrid, 1998, p. 338
} 
podría influir en los ciudadanos en razón de la diferencia impositiva perfilada en relación con la calificación energética que obtenga la vivienda.

\section{Justificación de su creación}

Los motivos que justifican la creación de incentivos fiscales para fomentar la mejora de la eficiencia energética en la vivienda habitual del propietario, a nuestro juicio, son los siguientes:

a) Necesidad de adaptar el parque inmobiliario español a las exigencias europeas relativas a la eficiencia energética de los edificios. Los últimos años han puesto de manifiesto que la Unión Europea (UE) se enfrenta a retos sin precedentes por la creciente dependencia de las importaciones de energía, escasez de recursos energéticos y necesidad de limitar el cambio climático. Por esta razón, desde 2006, la UE viene poniendo en marcha planes nacionales de acción sobre la eficiencia energética para asegurar la sostenibilidad del consumo de recursos energéticos ${ }^{28}$. Al punto que, a inicios de 2007, se estableció el objetivo primordial ahorrar un $20 \%$ en el consumo de energía de la UE en comparación con los valores previstos.

Aunque en los años siguientes $(2010,2011)$ pocos han sido los resultados, para avanzar decididamente en ello se ha incorporado la Directiva 2012/27/UE, del Parlamento Europeo y del Consejo, relativa a la eficiencia energética, mediante el cual se ha creado un marco común para fomentar la eficiencia energética en la UE con acciones que ponen en práctica propuestas del Plan de Eficiencia Energética 2011 para llegar a 2020 con un ahorro del 20\% en el consumo de energía de la UE, así como para conseguir nuevas mejoras de la eficiencia energética más allá de 2020 .

Para el sector de la edificación, la Directiva 2012/27/UE remarca que la mayor parte de los edificios de la UE son antiguos y que los mismos constituyen un enorme potencial de ahorro de energía debido a que representan el $40 \%$ del

\footnotetext{
${ }^{28}$ Directiva 2006/32/CE del Parlamento Europeo y del Consejo, de 5 de abril de 2006, sobre la eficiencia del uso final de la energía y los servicios energéticos (DO L 114 de 27.4.2006, p. 64).
} 
consumo de energía final de la UE. Por esta razón, aconseja a los Estados miembros a crear estrategias a largo plazo (incluso para después de 2020) que movilicen inversiones en la renovación de edificios residenciales y comerciales para la mejora del rendimiento energético del parque inmobiliario. En este sentido, destaca que el ritmo de renovación de edificios debe ir aumentando por cuanto los edificios son cruciales para alcanzar el objetivo de la UE de reducir las emisiones de gases de efecto invernadero entre un $80 \%$ y un $95 \%$ para 2050 respecto a $1990^{29}$. He ahí la primera razón justificativa.

b) Necesidad de rehabilitación del parque edificado español hasta el presente. Los últimos datos oficiales del parque de viviendas construidas en España evidencian la necesidad de intervenciones de rehabilitación y renovación urbana. Ya en 2013 las viviendas construidas en España ascendían a 25.208.622, y de este parque edificado, aproximadamente el 55\% (13.759.266) es anterior al año 1980 y casi el $21 \%$ (5.226.133) cuentan con más de 50 años. A ello se une el dato significativo que la gran mayoría han sido construidos sin criterios de eficiencia energética ${ }^{30}$.

Frente a tan evidente necesidad, el legislador estatal, en su primer intento de cambiar los actuales parámetros de las actuaciones urbanísticas, ha promulgado la Ley 8/2013 de 26 de junio ${ }^{31}$, marcando como objetivo prioritario la regeneración y rehabilitación urbana frente a la promoción de vivienda nueva. Con este fin, ha incorporado las condiciones básicas que ayuden a garantizar un desarrollo sostenible y eficiente del medio urbano mediante el fomento de la rehabilitación de los tejidos urbanos existentes. Ha procedido también, por primera vez, a ampliar el derecho de conservación del propietario, haciendo

\footnotetext{
${ }^{29}$ Sobre los problemas jurídicos que se plantean con la tributación del comercio de derechos de emisión de gases de efecto invernadero en la Unión Europea, puede consultarse URQUIZU CAVALLÉ, A: La naturaleza tributaria parafiscal de la carga pecuniaria derivada del régimen de comercio de derechos de emisión de gases de efecto invernadero de la Unión Europea en el sector aéreo. Calificación y problemas jurídicos, en Urquizu A., Políticas de protección ambiental en el siglo XXI: medidas tributarias, contaminación ambiental y empresa, Ed. Bosch, Barcelona, 2013, pp. 333-417.

${ }^{30}$ MERINO ESCARTÍN, J.F.: Resumen de la Ley de Rehabilitación, regeneración y renovación urbanas. Recuperado el 10-9-2017, de http://www.notariosyregistradores.com/doctrina/resumenes/2013rehabilitacion.htm\#eficiencia.

${ }^{31}$ BOE núm. 153, de27 junio 2013.
} 
hincapié en el deber de los propietarios de mantener los inmuebles en adecuadas condiciones de conservación. Con este deber, como apunta Gaja Díaz, se intenta desbloquear la inactividad en materia de actuaciones de transformación urbanística $^{32}$.

c) Necesidad de sustentar la viabilidad económica de la rehabilitación urbana. Si bien la estrategia de la renovación de edificios residenciales es una medida positiva por cuanto las reformas están dirigidas a reducir el consumo tanto de energía suministrada como de energía final de los edificios en un porcentaje significativo con respecto a los niveles anteriores a la renovación, dando lugar a un alto rendimiento energético, en esta tarea tiene mucho que ver la viabilidad económica de la reforma.

Algunos autores ya han puntualizado, después de valorar las medidas de rehabilitación que introdujo la Ley 8/2013, que "la mayor dificultad a que se enfrentan las operaciones de transformación, renovación y rehabilitación es su financiación"33. Efectivamente lo es. Por más buena intención y conciencia con el medio ambiente que tenga el consumidor final, si finalmente el acceder a reformas de su vivienda con el uso de materiales más eficientes que contribuyan a una construcción más sostenible, le supone un elevado costo, éste declinará por el uso de los materiales tradicionales que sean más asequibles a su economía. Piénsese que solo el coste de los materiales en una obra representa el $50 \%$ del coste total de una edificación ${ }^{34}$. Ello sin tener en cuenta el coste de los equipos, electrométricos y demás accesorios que se incorporan en la obra. En varios casos el precio final de los equipos/electrodomésticos con un consumo de energía menor suele ser superior al precio de aquellos que no tienen tales características. Por ejemplo, el costo de un calentador de agua a gas con sistema de condensación que incluye sistemas de ahorro de energía (estos son los que

\footnotetext{
${ }^{32}$ GAJA DÍAZ, F.: "La regeneración urbana en la encrucijada", Architecture, City and Environment, año 9, núm. 27, febrero 2015, p.15

${ }^{33}$ Ibidem, p. 15

34 ARENAS CABELLO, F.: Los materiales de construcción y el medio ambiente, Revista española electrónica de Derecho Ambiental, núm.17, junio 2008. Recuperado el 10-9-2017, de http://huespedes.cica.es/gimadus/17/03_materiales.html.
} 
llevan la etiqueta ErP-2015 nueva normativa europea) sale aproximadamente 1.240 euros o más, importe que cuadriplica el costo de un calentador de agua a gas normal, cuyo precio llega alrededor de 239 euros. No es de sorprender por ello que la propia Directiva 2012/27/UE impulse a que "los Estados miembros deban fomentar el empleo de mecanismos de financiación para promover los objetivos de eficiencia energética la presente Directiva"35.

Planteadas estas tres razones que a nuestro juicio justifican la creación de incentivos para la mejora de la eficiencia energética en la vivienda de construcción antigua, cabe preguntarnos para que servirían estos incentivos y qué resultados podrían reportar en los contribuyentes. Entre los principales resultados que se podría conseguir consideramos los siguientes:

a) Generar un impacto positivo reconduciendo los hábitos del consumidor final. Tal impacto positivo se deduce considerando que los incentivos fiscales, tal y como destaca la doctrina, pueden "ejercer una influencia considerable sobre los hábitos de consumo y de comportamiento de los consumidores" ${ }^{\text {36 }}$. Es precisamente esta influencia en los consumidores lo que ha llevado a utilizar a los beneficios fiscales como técnica estimulatoria en las mejoras introducidas en la gestión ambiental ${ }^{37}$. Así, nos dice Bokobo, que el incentivo en la fiscalidad funciona no como instrumento recaudatorio, o no solo como tal, sino como motivador de conductas, puesto que los incentivos son "creados para cambiar el comportamiento de los productores consumidores utilizando los efectos económicos del impuesto en un sentido orientador que beneficie a la tutela ambiental, incidiendo en las consecuencias de los sujetos afectados, bien disuadiéndoles de continuar en determinadas líneas de acción, o bien estimulándoles en la adopción de otras. ${ }^{\text {38 }}$.

b) Contribuir al cuidado del medio ambiente mediante construcciones sostenibles. Por cuanto el incentivo fiscal constituiría un sustento significativo que apoyaría la viabilidad económica de la rehabilitación o reforma de la vivienda que hoy por hoy vendría a ser un impulso relevante para que el propietario decida

\footnotetext{
${ }^{35}$ Apartado 50 de la Directiva 2012/27/UE, p.8.

${ }^{36}$ ROSEMBUJ, T.: El impuesto ambiental, Ed. El fisco, Barcelona, 2009, p. 127.

${ }^{37}$ Ibidem, 127.

${ }^{38}$ BOKOBO MOICHE, S., Gravámenes e incentivos fiscales ambientales, Ed. Civitas, 2000, p.86.
} 
reformar su vivienda con la incorporación de equipos eficientes energéticamente y materiales no perjudiciales para el medio ambiente. Decimos que sería un impulso porque la sociedad cada vez más está concienciada por la necesidad de defensa de nuestro ecosistema ${ }^{39}$. Demanda que los causantes de daños al medio ambiente sean quienes asumen su coste por la reparación en su integridad del medio afectado o su resarcimiento mediante el pago de los daños y perjuicios ocasionados (principio quien contamina paga ${ }^{40}$, pero también ya comienza a tomar conciencia del rol que desempeña a título particular con el cuidado del medio ambiente. Y especialmente con el consumo de energía debido a la difusión mayor del problema del cambio climático, que como se indica desde una perspectiva internacional: "Climate change is a matter of great concern for policymarkers and might have a disproportionate impact on developing countries, which contributed least to the causes of this phenomenon. Many factors have been suggested to influence CO2, but generaly energy consumption, growing with economic expansions, has been singled out as having the most adverse effect on the environment" ${ }^{41}$, es motivo de gran preocupación por el efecto adverso que tiene sobre el medio ambiente.

c) Facilitar el acceso a la vivienda aumentando el mercado de viviendas. En virtud que con la rehabilitación de las viviendas antiguas se aumentaría el mercado de pisos disponibles para la compra o alquiler de las mismas. Hay que tener en cuenta que según las cifras del INE de 2016, dos de los 3,5 millones de pisos desocupados que hay en España necesitan reforma por el mal estado en el que se encuentra la inmensa mayoría de ellos ${ }^{42}$. Muchos de estos pisos se encuentran básicamente en sus condiciones originales, con evidente deterioro físico de sus

\footnotetext{
${ }^{39}$ LOZANO CUTANDA, B.: "El nuevo sistema de responsabilidad ambiental para reparación de los daños ecológicos y puros", en Esteban Pérez, Estanislao Arana, Pedro Mercado y J. Luis Serrano (eds.), Derecho, Globalización, Riesgo y Medio ambiente, Ed. Tirant lo Blanch, Valencia, 2012, p. 453.

${ }^{40}$ Ibídem, pp. 453-454.

${ }^{41}$ MAJOCCHI, A.: "Mega-cities, urbanization, and public transport: a perspective on developing countries", en Lin-Heng Lye, Janet Milne, Hope Ashiabor, Larry Kreiser, Kurt Deketelaere (eds.), Critical issues in environmental taxation. International and comparative perspectives, Vol. VII, Ed. Oxford University, New York, 2009, p.33

42 ¿Qué hacen las administraciones con los pisos vacíos? La Vanguardia, 10/10/2016. Recuperado el 109-2017, de http://www.lavanguardia.com/vida/20161016/411001635131/pisos-vacios-catalunya.html.
} 
dotaciones y bajas condiciones de habitabilidad, razón por el cual no pueden ser vendidas ni alquilados.

Una vez rehabilitados estos pisos podrían ser un atractivo valorable para los particulares que carecen de vivienda, dado que como generalmente tales edificaciones suelen concentrarse en los cascos antiguos de las poblaciones los mismos se benefician "de unos mejores servicios (cantidad y proximidad) debido al modelo urbanístico en el que se construyeron, frente a las nuevas viviendas que se suelen encontrar en zonas peor comunicadas por transporte público, con menores servicios en cantidad y en tipología” ${ }^{43}$. Piénsese, además, que con la actividad de la rehabilitación de las viviendas existentes se podría generar también un impacto positivo en la recuperación económica del país porque se crearía empleos en el sector de la construcción; aspecto importante en la actualidad dado el problema del paro persiste, en el mes de agosto del año en curso el Servicio Público Estatal registró el dato de 3.382.324 personas en desempleo ${ }^{44}$.

\section{Su "vinculación" con la propiedad}

La incorporación de la propiedad a la política ambiental supone reforzar el uso de los incentivos económicos fundamentalmente porque la propiedad de un inmueble tiene una vocación perpetua.

En la propiedad subsiste un propósito de conservación y transmisión que la hace mejor para la gestión ambiental. Como señala Rosembuj, la gestión del propietario no puede asimilarse al del empresario. Primero porque su interés, siendo el rendimiento, no se agota exclusivamente en el aspecto económico. El propietario equilibra distintas vocaciones entre las que cuenta la lúdica, paisajista, pero que no culmina exclusivamente en el puro y duro cálculo económico. Segundo, porque el propietario tiende a trasmitir su dominio, normalmente a su familia, en buenas condiciones, en

\footnotetext{
43 BARTA, J. "La compra de pisos antiguos: riesgos y oportunidades". Recuperado el 10-9-2017, de http://www.josebarta.com/2011/10/04/la-compra-de-pisos-antiguos-riesgos-y-oportunidades/.

${ }^{44}$ Consultar: $\quad$ https://www.sepe.es/contenidos/comunicacion/noticias/paro-registrado-sube-46400personas-agosto.html (Recuperado el 15-9-2017).
} 
donde no solo cabe computar el estado o situación económica, sino el buen grado de conservación natural, paisajista y ambiental ${ }^{45}$.

Es precisamente por estas cualidades que encontramos en la propiedad que defendemos la aptitud positiva de la propiedad para su vinculación con el incentivo fiscal dirigido a la mejora de la eficiencia energética de la vivienda.

Creemos, en la misma línea de Sainteny y Rosembuj, que el propietario ordinario que actúa con diligencia normal, al no tender a la especulación inmobiliaria en breve transcurso del tiempo u obtención del máximo rédito del uso del suelo en el corto plazo "puede ser un aliado del desarrollo sostenible porque este no se puede concebir sino a largo plazo",46.

Este desarrollo sostenible que se conseguiría con la rehabilitación de los edificios residenciales existentes se plasmaría principalmente en la transferencia de un patrimonio conservado, custodiado y valorizado a las generaciones futuras del propietario del inmueble debido a que la rehabilitación de la vivienda se realizaría siguiendo criterios medioambientales para una mejor eficiencia energética de la misma.

\section{Configuración, delimitación y transcendencia}

Como instrumento de fomento de la eficiencia energética en las viviendas antiguas, los incentivos fiscales creados con esta finalidad deben internalizar acciones externas para estimular al consumidor el ahorro energético y empleo de energías renovables, para lo que será necesario tener en cuenta aspectos como los hábitos de las familias españolas, las características del producto energético, tipos de fuentes de energías renovables, la mejora de la eficiencia energética en la vivienda tras su reforma con incorporación en la construcción de las instalaciones o equipos eficientes energéticamente, así como la diferencia entre el ahorro inicial de energía esperado de una mejora de eficiencia y el consumo final de energía, denominado comúnmente como "efecto de rebote"47.

\footnotetext{
${ }^{45}$ ROSEMBUJ, T: “El impuesto ambiental...” ob. cit., pp. 184 y 185.

${ }^{46}$ Ibidem, p. 185.

${ }^{47}$ FREIRE-GONZÁLEZ, J.; FONT VIVANCO, D.; PUIG VENTOSA, I.: Economic structure and energy savings from energy efficiency in households, Ecological Economics, 2016, p. 12. El efecto de rebote está siendo principalmente discutido con respecto a los usos energéticos y analizado desde diferentes ámbitos y niveles económicos. Así, según Freire, Font y Puig, el estudio del efecto rebote "es importante en la planificación de las políticas energéticas, ya que el efecto de rebote indirecto produce cambios
} 
Una vez planteada la vía correspondiente para su introducción, sea en los impuestos directos o indirectos según tenga mejor adecuación y sea aconsejable por los resultados previsibles, existen diferentes propuestas que se podrían tomar en consideración. Por ejemplo, los ayuntamientos podrían establecer una bonificación en el IBI en función de las emisiones contaminantes, como se ha seguido en el caso de los coches con el Impuesto sobre Vehículos de Tracción Mecánica (IVTC) ${ }^{48}$; de esta forma, la eficiencia y la vivienda deben considerarse de manera tal que la construcción más eficiente sea bonificada.

Otra vía posible sería mediante una bonificación en el ICIO, donde eficiencia energética y la vivienda estarían consideradas también de forma conjunta, debido a que la construcción más eficiente sería bonificada, siendo por tanto el incentivo un aliciente para mejorar el comportamiento ambiental del propietario plasmado en su vivienda, lo cual es importante más que nada dada la alta dependencia energética de España. De otra parte cabe la posibilidad de introducir el incentivo en el IRPF, donde cabe dos posibilidades de su configuración: por un lado, el incentivo podría configurarse como una deducción, tal como sucedía con la deducción por rehabilitación de la vivienda habitual, pero en este caso vendría orientado a la rehabilitación que mejore la eficiencia energética de la vivienda de construcción antigua. Y, por otro lado, el incentivo podría configurarse como una deducción vinculando el incentivo a un Programa Estatal de Vivienda ${ }^{49}$.

También se introduciría el incentivo bajo otros modelos que se han establecido a nivel internacional, como es el caso de Estados Unidos, donde se creó incentivos de esta naturaleza en el periodo 2001 a 2015, que consistían en la deducción en la cuota del $20 \%$ del precio de adquisición de nuevas viviendas con equipamientos energéticoseficientes; deducción en cuota del $20 \%$ del precio de adquisición de diverso

inesperados en el consumo de energía. Si el efecto de rebote no se considera al diseñar políticas de eficiencia energética, las medidas de eficiencia energética no serán tan efectivas como se esperaba", p. 18.

${ }^{48}$ En el IVTC existe una bonificación del 75\% en la cuota para los vehículos que consuman combustibles menos contaminantes (biogás, gas natural comprimido, gas licuado, metanol o hidrogeno, diesel híbrido o eléctrico) y vehículos cuyas características de motor tienen menos incidencia negativa en el medio ambiente (art. 95.6, a) y b) del TRLHL).

${ }^{49}$ En este caso, el beneficio fiscal podría desarrollarse en cierta línea con lo que se aplicó en el periodo 2009-2012. Como vimos precedentemente, desde la entrada en vigor del Real Decreto 6/2010, de 9 de abril hasta el 31/12/2012, en el IRPF se permitía deducir el 10\% de las cantidades satisfechas para la realización de obras en la vivienda habitual que tengan por objeto la mejor de la eficiencia energética, la higiene, salud y protección del medio ambiente, entre otras mejoras contempladas en el Plan Estatal de Vivienda y rehabilitación 2009-2012 aprobada por el Real Decreto 2066/2008, de 12 de diciembre. 
equipamiento energético-eficiente en casas y edificios; deducción en cuota del 15\% sobre el coste de adquisición e instalación de sistemas de energía solar ${ }^{50}$.

Ahora bien, la transcendencia económica de este tipo de incentivos fiscales sería notorio toda vez que la renovación energética de los edificios españoles genera una situación ventajosa tanto para el sector público como para el privado. Para el propietario el incentivo es un incentivo económico, mientras que para el legislador es un instrumento eficaz por medio del cual puede internalizar los costes ambientales de un determinado sector. Y es que, la costosa dependencia energética de España puede ser abordada en parte reduciendo de manera rentable la ineficiencia energética. La mejora de la eficiencia energética en los edificios puede contribuir además de manera directa e indirecta a la creación de empleo sin implicar un coste neto para el sector público. En este sentido, gracias a la renovación energética, las viviendas y edificios españoles podrían adquirir un mayor valor y ser más cómodos y productivos.

\section{REFLEXIONES FINALES}

Teniendo en cuenta todo lo expuesto en el trabajo concluimos señalando las siguientes reflexiones finales:

1. Fomentar el ahorro y la eficiencia en los hogares debería ser un aspecto fundamental de la política energética a pequeña y gran escala, porque la eficiencia en el uso de la energía de la vivienda representa un importante potencial para mitigar los efectos del consumo energético y su impacto en el problema del cambio climático.

2. Para ello no sólo es fundamental crear conciencia en los ciudadanos de respeto medioambiental y del ahorro en el uso de energía en la vivienda, sino también crear incentivos que lo promuevan. En este sentido, las medidas tributarias plasmadas en incentivos fiscales pueden constituir un medio eficaz para potenciar la eficiencia energética, por cuanto coadyuvan a conseguir un mejor comportamiento ambiental en los contribuyentes.

3. Este aspecto es fundamental en el contexto actual puesto que, como constatamos en el estudio, no encontramos incentivos fiscales para la eficiencia energética de las viviendas

\footnotetext{
${ }^{50}$ GAGO RODRÍGUEZ, A.; LABANDEIRA VILLOT, X.; RODRÍGUEZ MÉNDEZ, M.: La práctica de la imposición ambiental y de las reformas fiscales verdes, en A. Gago y X. Labandeira (Dirs.), Energía, Fiscalidad y Medio ambiente en España, Ed. Instituto de Estudios Fiscales, Madrid, 2002, p. 109.
} 
que estén incorporados en la normativa tributaria que incide en la propiedad, como son el IBI e IP, o bien en otros impuestos que afectan al propietario como son el ICIO e IRPF. Apenas existen referencias a bonificaciones potestativas en el IBI y en el ICIO. El único incentivo centrado en la eficiencia energética se incorporó en el IRPF, pero ha sido suprimido en 2012.

4. Si se promueve una estrategia de renovación de los edificios de nueva construcción como existentes acorde a la Directiva Europea de Eficiencia Energética, al Real Decreto 235/2013 y al CTE, a través de una plataforma legislativa, tributaria y financiera sólida se pueden obtener múltiples beneficios. Es esencial por ello trabajar más en conseguir que el certificado energético de la vivienda deje de ser visto por los compradores y vendedores como un mero trámite y se avance más hacia la materialización de las mejoras que el certificado recomienda al propietario para mejorar el consumo energético de su vivienda.

\section{BIBLIOGRAFÍA}

ANGULO ARAMBURU, J.; CHICO DE LA CÁMARA, P.; GARCÍA BAQUERO, C.; HERRERA MOLINA, P.; MONREAL PALOMINO, I.: El tratamiento fiscal de las nuevas energías, en A. Gago y X. Labandeira (Dirs.), Energía, Fiscalidad y Medio ambiente en España, Ed. Instituto de Estudios Fiscales, Madrid, 2002.

ARANDA USÓN, A., et. al.: Eficiencia energética en instalaciones y equipamiento de edificios, Ed. Prensas Universitarias de Zaragoza, Zaragoza, 2010.

ARENAS CABELLO, F.: Los materiales de construcción y el medio ambiente, Revista española electrónica de Derecho Ambiental, núm.17, junio 2008. Recuperado el 10-92017, de http://huespedes.cica.es/gimadus/17/03_materiales.html.

BARTA, J. "La compra de pisos antiguos: riesgos y oportunidades". Recuperado el 109-2017, de http://www.josebarta.com/2011/10/04/la-compra-de-pisos-antiguos-riesgosy-oportunidades/.

BOKOBO MOICHE, S., Gravámenes e incentivos fiscales ambientales, Ed. Civitas, 2000 .

GAGO RODRÍGUEZ, A.; LABANDEIRA VILLOT, X.; RODRÍGUEZ MÉNDEZ, M.: La práctica de la imposición ambiental y de las reformas fiscales verdes, en A. Gago y 
X. Labandeira (dirs.), Energía, Fiscalidad y Medio ambiente en España, Ed. Instituto de Estudios Fiscales, Madrid, 2002.

GAJA DÍAZ, F.: "La regeneración urbana en la encrucijada", Architecture, City and Environment, año 9, núm. 27, febrero 2015.

GARCÍA-TORRES FERNÁNDEZ, M.J.: "La protección atmosférica en Andalucía: Estudio del gravamen sobre las emisiones a la atmósfera", en Derecho, Globalización, Riesgo y Medio ambiente, Ed. Tirant lo Blanch, Valencia, 2012.

Instituto para la Diversificación y Ahorro de la Energía: "Las claves para conocer y actuar en materia de Certificación Energética de los Edificios”, 2015. Recuperado el 109-2017, de http://www.idae.es/uploads/documentos/documentos_Las_claves_para_conocer_y_actu ar_en_materia_de_CEE_20151007_Comentarios_d3402fed.pdf.

LOZANO CUTANDA, B.: "El nuevo sistema de responsabilidad ambiental para reparación de los daños ecológicos y puros”, en Esteban Pérez, Estanislao Arana, Pedro Mercado y J. Luis Serrano (eds.), Derecho, Globalización, Riesgo y Medio ambiente, Ed. Tirant lo Blanch, Valencia, 2012

MAJOCCHI, A.: "Mega-cities, urbanization, and public transport: a perspective on developing countries”, en Lin-Heng Lye, Janet Milne, Hope Ashiabor, Larry Kreiser, Kurt Deketelaere (eds.), Critical issues in environmental taxation. International and comparative perspectives, Vol. VII, Ed. Oxford University, New York, 2009.

MERINO ESCARTÍN, J.F.: Resumen de la Ley de Rehabilitación, regeneración y renovación urbanas. Recuperado el 10-9-2017, de http://www.notariosyregistradores.com/doctrina/resumenes/2013rehabilitacion.htm\#efic iencia.

P. CHICO DE LA CÁMARA, P.; GRAU RUIZ, M. A.; HERRERA MOLINA, P.: "Incentivos a las energías alternativas como instrumento de desarrollo sostenible", Quincena Fiscal, Núm. 2/2003.

REDDY, S.; ASSENZA, G.; ASSENZA, D.; HASSELMANN, F.: Energy efficiency and climate change: conserving power for a sustainable future, Ed. Sage Publications India Pvt Ltd., New Dheli, 2009.

ROSEMBUJ, T.: El impuesto ambiental, Ed. El fisco, Barcelona, 2009. 
ROZAS VALDÉS, J.A.: "El impuesto sobre la electricidad”, en R. Falcón y Tella (Dir.), Medidas Fiscales para 1998, Ed. Marcial Pons, Madrid, 1998.

ROZAS VALDÉS, J. A.: «Evolución y reforma del sistema financiero de la energía eléctrica», Crónica Tributaria, nº 150, 2014.

RUIZ RIVERA, R.: Calificación energética de los edificios.ENACO108, $1^{\circ} \mathrm{Ed}$., IC

Editorial, Málaga, 2014. Recuperado el 10-9-2017, de https://books.google.es/books?id=jNKNCwAAQBAJ\&pg=PT69\&dq=las+viviendas+en + Espa $\% \mathrm{C} 3 \% \mathrm{~B} 1 \mathrm{a}+$ consumen $+\mathrm{el}+17 \% 25+\mathrm{de}+$ toda + la + energia + del + pais $\&$ hl $=$ es.

SALIDO COBO, J.: La eficiencia energética en la vivienda, tan crucial como ignorada. Recuperado el 10-9-2017, de http://www.elmundo.es/economia/2015/03/13/5501ede7e2704e78348b4575.html.

URQUIZU CAVALLÉ, A: La naturaleza tributaria parafiscal de la carga pecuniaria derivada del régimen de comercio de derechos de emisión de gases de efecto invernadero de la Unión Europea en el sector aéreo. Calificación y problemas jurídicos, en Urquizu A., Políticas de protección ambiental en el siglo XXI: medidas tributarias, contaminación ambiental y empresa, Ed. Bosch, Barcelona, 2013.

World Energy Council (WEC): Survey of Energy Resources. Londres, Reino Unido, 2010, p.201. Recuperado el 10-9-2017, de https://www.worldenergy.org/wpcontent/uploads/2012/09/ser_2010_report_1.pdf. 